ISSN 2236-0859

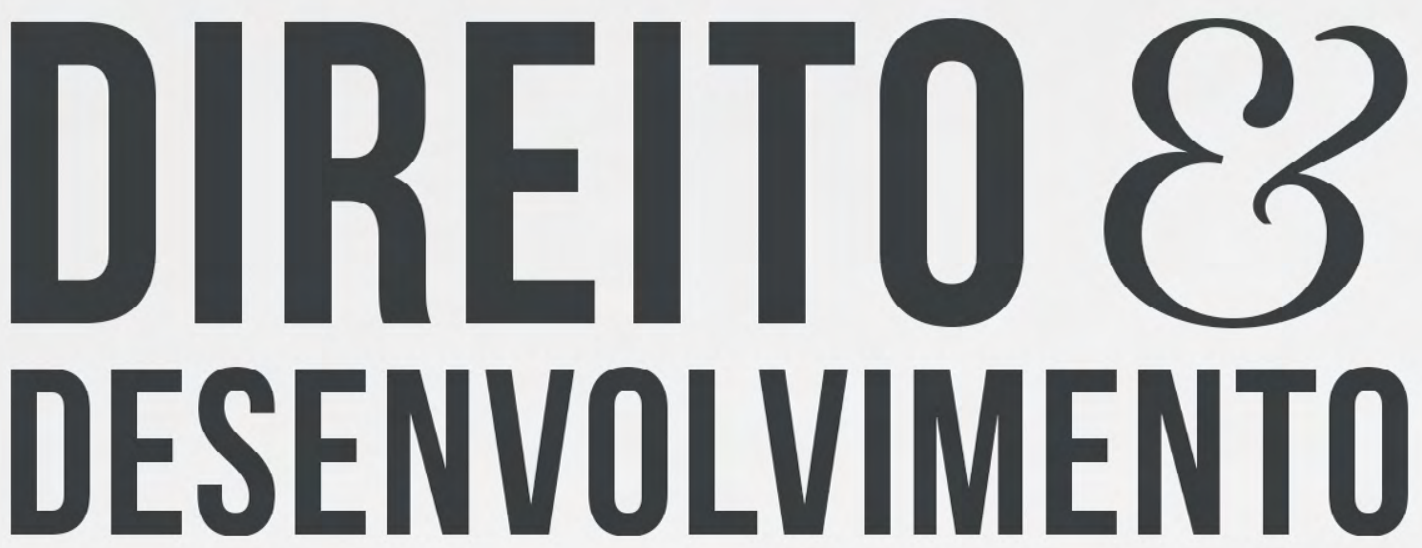

REVISTA DO PROGRAMA DE PÓS-GRADUAÇÃO EM DIREITO MESTRADO EM DIREITO E DESENVOLVIMENTO SUSTENTÁVEL

A CONVENÇÃO 169 DA OIT E A AGENDA 2030DA ONU: O DIREITO DE CONSULTA PRÉVIA DAS COMUNIDADES LOCAIS NAS OBRAS DE GRANDE VULTO

ALEXANDRE ANTONNIO BRUNO DA SILVA MARLÉA NOBRE DA COSTA MACIEL 


\title{
A CONVENÇÃO 169 DA OIT E A AGENDA 2030 DA ONU: O DIREITO DE CONSULTA PRÉVIA DAS COMUNIDADES LOCAIS NAS OBRAS DE GRANDE VULTO
}

\section{ILO CONVENTION 169 AND THE 2030 AGENDA: THE RIGHT OF PRIOR CONSULTATION OF LOCAL COMMUNITIES IN WORKS OF GREAT VULT}

Recebido: 04/11/2017

Aprovado: 11/02/2018
Alexandre Antônio Bruno da Silva* Marléa Nobre da Costa Maciel ${ }^{* *}$

RESUMO: Este artigo teve o propósito aliar o direito de consulta previsto na Convenção 169 da OIT com a Agenda 2030 da ONU. A junção desses instrumentos buscou abordar a possibilidade de aplicação do direito de consulta prévia previsto no art. 6o da Convenção 169 da OIT para além dos povos indígenas e tribais, estendendo-se para grupos e comunidades locais que estiverem na iminência de sofrer um impacto socioambiental a ser causado por uma obra de grande vulto. O estudo fundou-se no desenvolvimento sustentável a partir da participação crítica e reflexiva das comunidades acerca de suas necessidades, dos recursos naturais e de sua identidade cultural. Para analisar o fenômeno, utilizou-se como base a pesquisa bibliográfica, por meio da análise de livros, artigos publicados em coletâneas e periódicos, normas nacionais e internacionais, entre outras fontes, que ilustrassem a presença do tema no contexto brasileiro, portanto, descritiva. A originalidade do artigo é atribuída à defesa da ampliação do público objeto da norma considerando-a uma interpretação não positivista. A conclusão mostrou a importância da utilização do direito de consulta prévia, de boa-fé e adequada previsto na Convenção como um importante instrumento de participação democrática e materializador dos direitos fundamentais, notadamente a dignidade das comunidades envolvidas.

Palavras-chave: Agenda 2030 da ONU. Convenção 169 da OIT. Comunidade Tradicional.

\begin{abstract}
This article had the purpose of allying the right of consultation provided for in ILO Convention 169 with 2030Agenda. The combination of these instruments sought to address the possibility of applying the right of prior consultation provided for in art. 6 of Convention 169 of the ILO beyond indigenous and tribal peoples, extending to groups and local communities that are imminent if it suffers a socioenvironmental impact to be caused by a work of great magnitude. The study was based on sustainable development based on the critical and reflexive participation of communities in their needs, natural resources and their cultural identity. In order to analyze the phenomenon, bibliographic research was used as a basis, through the analysis of books, articles published in collections and periodicals, national and international norms, among other sources, to illustrate the presence of the theme in the Brazilian context, therefore, descriptive. The originality of the article is attributed to the defense of the extension of the public object of the norm considering it in a non-positivist interpretation. The conclusion showed the importance of using the right of prior, bona fide and adequate consultation provided for in the Convention as an important instrument of democratic participation and materializing of fundamental rights, in particular the dignity of the communities involved.
\end{abstract}

Keywords: The 2030 Agenda. ILO Convention 169. Traditional Community.

\footnotetext{
* Doutor em Direito pela PUC-SP. Doutorando em Políticas Públicas pela UECE. Mestre em Direito pela UFC. Mestre em Informática pela PUC-RJ. Professor do Programa de Mestrado em Direito do Centro Universitário Christus (UNICHRISTUS). E-mail: alexandre_bruno@terra.com.br

** Mestranda em Processo e Direito ao Desenvolvimento pelo Centro Universitário Christus (UNICHRISTUS). Especialista em Trabalho e Processo do Trabalho pelo Centro Universitário Christus. E-mail: marleanobre@hotmail.com
} 


\section{INTRODUÇÃO}

Obras de grande vulto, principalmente as que ocorrem em áreas longínquas, trazem o desenvolvimento (regional ou nacional) como seu fundamento e promessa. Entretanto, em sua execução e depois dela, geralmente originam mazelas e impactos socioambientais. A mera contratação de trabalhadores masculinos de outras regiões do país causa uma série de transtornos. A migração em quantidade volumosa deixa sequelas na localidade e nos próprios trabalhadores. Estes, não raramente, sofrem devido às condições, muitas vezes, precárias em que vão trabalhar e viver. As dores ocasionadas pelo desenraizamento afetivo de seu local de origem também são sentidas.

A Convenção 169 da Organização Internacional do Trabalho (OIT), aplicável aos povos indígenas e tribais de países independentes, estabelece para estes o direito de definir suas próprias prioridades de desenvolvimento na medida em que afetem suas vidas, crenças, instituições, valores espirituais e a própria terra que ocupam ou utilizam. A importância dessa medida como elemento da participação popular justifica que seja verificada a possibilidade de utilização dessa convenção, para além dos grupos expressamente favorecidos por seu conteúdo normativo (OIT, 1989).

O direito de consulta prévia, livre e informada, encontra-se no art. 6o da Convenção 169 da OIT. Esse instrumento, que não nega ou exclui qualquer forma de participação democrática brasileira, tem significância ímpar. O seu conteúdo é revestido de uma principiologia ética e moral coletiva que vai além da participação em audiências públicas. É calcado na não discriminação, no valor do reconhecimento da identidade cultural, e no modo de vida de todos os afetados (OIT, 1989).

A boa-fé expressa no art. 6o, item 2 da Convenção define que as partes devem se empenhar e dirigir esforços para a obtenção de um resultado respaldado no consenso. Após tomada a decisão, esta passaria a vincular as partes, o que resulta numa participação democrática efetiva e materializada por meio de um diálogo significativo. Indo-se muito além de um mero referendo, em que haja duas respostas possíveis: sim ou não (DINO, 2014).

A intenção é colocar o trabalhador local e a comunidade como protagonistas de suas vidas. Estes devem ter acesso prévio e em tempo hábil, à formulação, à implementação e à avaliação de planos e programas de desenvolvimento que possam afetá-los. Desta forma, podem analisar e fazer as considerações que entenderem ser importantes para o exercício de suas liberdades subjetivas e para o desenvolvimento coletivo vivenciando a autodeterminação.

O conteúdo normativo da Convenção, se interpretado sob um viés restritivo, não alcança a aplicação que se defende nesse estudo. Entretanto, encontra-se totalmente condizente com a Agenda 2030 para o Desenvolvimento Sustentável, plano de ação para as pessoas, para o planeta e para a prosperidade das Nações Unidas (ONU, 2015).

A agenda, criada em 2015, estabelece metas que estimularão a ação até o ano de 2030 em áreas de importância crucial para a humanidade e para o planeta. Em relação às pessoas, determina-se a acabar com a pobreza e a fome, em todas as suas formas e dimensões, e garantir que todos os seres humanos possam realizar o seu potencial em dignidade e igualdade, em um ambiente saudável. Como esse objetivo, o planeta deve ser protegido da degradação, sobretudo por meio do consumo e da produção sustentáveis, da gestão sustentável dos seus recursos naturais, para que ele possa suportar as necessidades das gerações presentes e futuras.

Visa-se garantir que todos os seres possam desfrutar de uma vida próspera e de plena realização pessoal, e que o progresso econômico, social e tecnológico ocorra em harmonia com a natureza. Além disso, promovem-se as sociedades pacíficas, justas e inclusivas que estejam livres do medo e da violência. "Não pode haver desenvolvimento sustentável sem paz e não há paz sem desenvolvimento sustentável" (ONU, 2015).

Por fim, as Nações Unidas determinam-se a mobilizar os meios necessários para implementar a Agenda por meio de uma Parceria Global para o Desenvolvimento Sustentável revitalizada, com base num 
espírito de solidariedade global reforçada, concentrada em especial nas necessidades dos mais pobres e mais vulneráveis e com a participação de todos os países, todas as partes interessadas e todas as pessoas. Realizadas as ambições em toda a extensão da Agenda, a vida de todos será profundamente melhorada e o mundo será transformado para melhor. Há um comprometimento de que ninguém será deixado para trás.

A metodologia utilizada tomou por base um estudo descritivo-analítico desenvolvido por meio de pesquisa bibliográfica e em meios oficiais de pesquisa. O referencial teórico foi, basicamente, fundado em trabalhos publicados em livros, artigos científicos, jurisprudência e repositórios oficiais que abordam a temática estudada.

\section{AS OBRAS DE GRANDE IMPACTO SOCIOAMBIENTAL E A CONTRATAÇÃO DA MÃO DE OBRA}

A realização de obras de grande vulto - principalmente grandes obras de engenharia, como hidrelétricas, barragens, ferrovias, complexos viários, extração mineral, polo industrial etc. - apresentase, a priori, como um investimento (público ou privado) que impacta no desenvolvimento do país e, em grande medida, também de uma região. Geralmente, são empreendimentos em áreas que se encontram em posições isoladas, mas que, estrategicamente, são necessárias para interligar regiões e escoar a produção (agrícola, mineral, madeireira, pecuária etc.), ou podem ser obras que visam explorar o potencial ambiental de uma região, causando interferência também em pequenas cidades.

Mesmo que se considere que tais investimentos (grandes obras, grandes empreendimentos, portanto grandes interferências) são necessários, certamente há que se verificar quais impactos socioambientais podem causar à região e ao seu entorno, à população envolvida, bem como na vida dos trabalhadores que servirão de massa produtiva para fazer acontecer tais empreendimento. Não serão somente positivos.

Essa preocupação é observada no Objetivo 8 da Agenda 2030, quando traz a promoção de um crescimento econômico voltado para o desenvolvimento e a inclusão. A execução de uma obra de grande monta deve - para atender às diretrizes do Objetivo - respeitar a vida e dar voz às escolhas daqueles que serão impactados, promover o desenvolvimento local aproveitando a mão de obra da região e, ao mesmo tempo, zelar por aqueles que se encontram em situação de migração ou deslocamento.

A migração e o deslocamento são temas tratados no item 8.8 da Agenda: "Proteger os direitos trabalhistas e promover ambientes de trabalho seguros e protegidos para todos os trabalhadores, incluindo os trabalhadores migrantes, em particular as mulheres migrantes, e pessoas em empregos precários" (ONU, 2015).

É certo que em decorrência da implantação de um grande projeto, existe a necessidade de suporte operacional e logístico que demanda centenas de pessoas em atividade nesses canteiros de obra. Essa gama de trabalhadores, em sua quase totalidade formada por homens, chega a representar uma desproporção demográfica em relação ao número de mulheres - contratadas ou residentes no entorno.

Tal fato demonstra a necessidade de um estudo socioambiental que tente minimizar os problemas que essa desproporção pode causar para a população local, principalmente porque obras de grande vulto demoram anos para serem concluídas. Exemplos e estudos pululam a demonstrar que, em não sendo observado um estudo socioambiental prévio, junto com o grande empreendimento somam-se sérios problemas socioambientais que são capazes de permanecer por décadas.

Portanto, é importante a preocupação com a contratação da mão de obra. Saber de onde ela vem e conhecer o perfil do contratado, por exemplo, é significativo e deve ser um elemento a ser posto em discussão com comunidade a ser atingida pela obra.

O estudo feito por RIGOTTO (2009, p. 2051), a fim de verificar os males que a termelétrica instalada no complexo industrial e portuário do Pecém/CE pode causar à população que vive no entorno, inserindo a temática da migração, aponta que: 
Estudos têm evidenciado, por outro lado, uma ampla gama de transformações territoriais resultantes destes projetos de desenvolvimento, que vão repercutir de variadas formas [...] Os processos migratórios de grandes contingentes de trabalhadores atraídos para a fase de construção dos empreendimentos, que colocam novas demandas de moradia, saneamento, educação, saúde, transporte, lazer. E uma perspectiva para o término da obra, já que muitas vezes não se enquadram no perfil demandado para a fase de operação do empreendimento. Já a migração para os centros urbanos e regiões metropolitanas está fortemente associada à violência, acidentes de trânsito, doenças sexualmente transmissíveis e aids, consumo de álcool e drogas ilícitas, doenças mentais e sofrimento psíquico, gravidez precoce, etc. Vários deles são resultantes dos efeitos da desterritorialização sobre os modos de subjetivação, a maneira como as pessoas moram, trabalham, se relacionam umas com as outras, elaboram sua expressão coletiva. (grifo nosso)

Igualmente, em recente reportagem sobre o tema nominada "A ferro e ouro", Thomas (2017, p. 84-91) narra e dialoga, com base nas experiências degradantes do passado, os possíveis impactos que a instalação de dois grandes projetos de mineração - a extração de minério de ferro pela Vale do Rio Doce e de ouro pela canadense Belo Sun - podem causar no Pará.

O exemplo estampado na reportagem relaciona-se com o conteúdo do presente artigo, pois, sobremaneira, traz a lume importante reflexão acerca das obras e interferências socioambientais que podem ocorrer a partir de empreendimentos dessa natureza, principalmente se acontecerem sem levar em consideração a realidade local, como, por exemplo, a necessária contratação da mão de obra dos trabalhadores que residem na região envolvida.

No mesmo sentido, são os impactos ocasionados em decorrência das obras da UHE de Belo Monte, principalmente, quando se faz o recorte sobre a grande migração de trabalhadores. Havia sido estabelecido pelos órgãos responsáveis pela análise do Estudo de Impacto Ambiental (EIA) condicionantes que estipulavam um percentual entre $60 \%$ a $70 \%$ para contratação de trabalhadores locais, mas de acordo com as informações extraídas do Instituto Socioambiental, estas nunca foram cumpridas.

Soma-se a esse fato, a ausência de participação democrática tanto por parte da comunidade envolvida, quanto pelos trabalhadores contratados para atuar no projeto SENA (2014, p. 73) ao estudar os trabalhadores nos canteiros de obra de Belo Monte afirma que "[...] as situações de imposição do projeto da usina, aliado ao modelo de desenvolvimento econômico [...] favorecem uma série de irregularidades e situações adversas, desde o processo de recrutamento, contratação, até as condições de vida [...] dos operários.”.

A contratação de mão de obra local, sem dúvida, se mostra apta para minimizar essas adversidades e para favorecer o desenvolvimento sob um viés que vai além do crescimento econômico, sendo capaz de promover a expansão das capacidades (SEN, 2010), das liberdades individuais e da autodeterminação das comunidades envolvidas. Mas, não só! A existência de maior número de trabalhadores locais, em vez de trabalhadores migrantes, contribui também para diminuir as interferências e males que, por vezes, um contingente masculino em grande quantidade pode causar, como, por exemplo, os rescaldos sociais da obra do rodoanel.

Assim, não basta que tenha maior riqueza de recursos circulando na região ou maior oferta de trabalho e emprego, é necessário que junto ao crescimento esteja havendo o desenvolvimento das pessoas e da comunidade, e que a elas tenha sido oportunizado vez e voz. Sob essa ótica, interessante a colocação, muito assemelhada à doutrina de Amartya Sen e Stefania Vaccaro (2012, p. 414):

Atualmente, temos que o desenvolvimento não é um consectário de qualquer crescimento e só ocorrerá efetivamente se a dinâmica econômica for capaz de transformar as estruturas sociais garantindo as liberdades individuais [...] e a distribuição de renda e de oportunidades de forma mais equitativa entre seus diferentes membros. 
Empreendimentos degrandevultogeralmente estãoassociadoscomageraçãodeemprego (direitos, indiretos e temporários), mas há que se questionar de onde vem a mão de obra para atender tal demanda, se há preferência para contratação de trabalhadores locais ou se a ocupação será predominantemente de trabalhadores migrantes. Sem dúvida, a consulta à população diretamente envolvida e de forma prévia é um meio para fazer esses ajustes.

No caso de uma obra ou empreendimento de ordem pública, o critério da sustentabilidade estabelecido no Decreto $n^{\circ} 7 \cdot 746 / 2012$ traz a preferência para a contratação de mão de obra local, como se vê:

Art. 4-São diretrizes de sustentabilidade, entre outras:

I - menor impacto sobre recursos naturais como flora, fauna, ar, solo e água;

II - preferência para materiais, tecnologias e matérias-primas de origem local;

III - maior eficiência na utilização de recursos naturais como água e energia;

IV - maior geração de empregos, preferencialmente com mão de obra local;

$\mathrm{V}$ - maior vida útil e menor custo de manutenção do bem e da obra;

VI - uso de inovações que reduzam a pressão sobre recursos naturais; e

VII - origem ambientalmente regular dos recursos naturais utilizados nos bens, serviços e obras. (BRASIL, 2012) (grifo nosso)

Da mesma forma, Instrução Normativa n ${ }^{\circ}$ o1, de 19 de janeiro de 2010 do Ministério do Planejamento Orçamento e Gestão - MPOG traz em seu bojo o mesmo tipo de preferência:

Art. $4^{\underline{0}}$ Nos termos do art. 12 da Lei nํㅛ 8.666, de 1993, as especificações e demais exigências do projeto básico ou executivo, para contratação de obras e serviços de engenharia, devem ser elaborados visando à economia da manutenção e operacionalização da edificação, a redução do consumo de energia e água, bem como a utilização de tecnologias e materiais que reduzam o impacto ambiental, tais como:

$\S$ Io-Deve ser priorizado o emprego de mão-de-obra, materiais, tecnologias e matérias-primas de origem local para execução, conservação e operação das obras públicas. (BRASIL, 2010) (grifo nosso)

Tais normas, no entanto, não expressam qual percentual deve se apresentar apto a cumprir suas diretrizes, mas é um elemento que pode fundamentar os argumentos da população diretamente evolvida no momento da luta por esse quinhão.

Um exemplo concreto do direito de aplicação de condicionantes (percentual de contratação de trabalhadores locais) extraído da reportagem "A ferro e ouro", acima mencionada, porém pactuadas pelo Ministério Público Federal, é que a contratação de 30\% dos trabalhadores que deverão atuar nas atividades da mineradora Belo Sun para extração do ouro do subsolo seja de trabalhadores locais e das regiões circunvizinhas, como se vê:

Enquanto isso, forma-se uma grande massa de desempregados na região. [...] Tem sido assim nos últimos cinco anos, desde que a Belo Sun começou a ocupar a área. Os moradores, contudo, alimentam a esperança de que todos passarão a ter emprego a partir do momento em que a mina ouro de Volta Grande começar a funcionar. A Belo Sun promete empregar 2100 trabalhadores quando chegar ao auge das obras e outros 526 na hora em que o empreendimento for inaugurado. Uma das condicionantes do MPF para que a mineração ocorra é que ao menos $30 \%$ dessa mão de obra seja proveniente de vilas e municípios próximo. (THOMAS, 2017, p. 84-91) (grifo nosso)

Essa determinação imposta pelo Ministério Público Federal para que haja a contratação de um mínimo de trabalhadores locais, como condição prévia à autorização e instalação do exercício da atividade, se apresenta como um meio de minimizar os impactos socioambientais que o tamanho do empreendimento pode causar. 
É interessante ressaltar que tal exigência se coaduna com a temática do desenvolvimento para além do crescimento econômico. Mas, não só, também tem a ver com o conteúdo do art. 170 da Constituição Federal, ou seja, com a necessária coexistência entre a valorização do trabalho e a livre iniciativa, tudo isso em busca de fortalecer a dignidade da pessoa humana, e, portanto, dos direitos fundamentais.

No Estado do Ceará, há em tramitação na Assembleia Legislativa o PL no 20/2017(CEARÁ, 2017) que versa sobre o estabelecimento de percentual para contratação de trabalhadores cearenses pelas empresas prestadoras de serviços nas áreas da construção civil, pesada, montagem e manutenção industrial:

PROJETO DE LEI N. 20/17. “DISPÕE SOBRE A ESTIPULAÇ̃̃O DE PERCENTUAIS DE VAGAS PARA CONTRATAÇÃO DE MÃO-DE-OBRA CEARENSE PELAS EMPRESAS PRESTADORAS DE SERVIÇOS DAS ÁREAS DE CONSTRUÇÃO CIVIL, CONSTRUÇÃO PESADA, MONTAGEM E MANUTENÇÃO INDUSTRIAL NO ESTADO DO CEARÁ E DÁ OUTRAS PROVIDÊNCIAS."A ASSEMBLEIA LEGISLATIVA DO ESTADO DO CEARÁ DECRETA:

Art. $1^{\circ}$. As empresas da construção civil, construção pesada, montagem e manutenção industrial prestadoras de serviços no Ceará deverão contratar e manter, de forma prioritária, trabalhadores domiciliados neste Estado, no percentual de $60 \%$ (setenta por cento) das vagas para homens e $10 \%$ (dez por cento) para mulheres, a fim de desempenhar as funções especificadas no anexo desta Lei.

Art. $4^{\circ}$. Compete ao Executivo, por meio dos órgãos competentes, fiscalizar o cumprimento desta Lei e impor sanções às empresas infratoras, contando com a colaboração dos Sindicatos das Categorias e Comissões de Representação da Classe Trabalhadora. (CEARÁ, 2017) (grifo nosso)

Porém, em que pese se verificar que essa temática está se firmando como atrelada ao direito fundamental de acesso ao trabalho, é importante que o protagonista dessas inquietudes seja a própria população interessada, ou seja, o próprio trabalhador fazendo valer seu direito a um emprego formal, justo, decente e regulado por normas protetivas. Isso não é fácil, mas deve ser uma luta constante, pois de acordo com o Ministro Lélio Bentes:

O maior desafio do Brasil é mostrar que é possível crescer economicamente valorizando os princípios de proteção social e promovendo a valorização do trabalho como elemento inerente aos direitos humanos. O desafio que se nos coloca neste momento é o de demonstrar que é possível consagrar um novo modelo de crescimento econômico. Um crescimento que favoreça o empreendimento, porque quem investe tem direito ao lucro, ao seu retorno, mas que também promova justiça social.

Todo ser humano tem direito ao trabalho, mas não a qualquer trabalho, e sim a um trabalho digno, desempenhado em condições justas e favoráveis, com uma retribuição que lhe permita uma vida nos níveis da dignidade humana (BRASIL, 2013).

Assim, é a comunidade que deve se organizar livremente e pleitear por direitos aptos a promover alterações na legislação, nas políticas públicas e em qualquer assunto que possa dizer respeito aos seus próprios interesses. Seja por meio do direito de ser previamente consultada, seja por meio de manifestações de inconformismo.

Tal afirmação aponta para autonomia, o despertar para a autodeterminação e a percepção de cada um na sua condição de agente. Sua efetiva atuação - com direito prévio à voz e à vez - é capaz de refrear interferências impactantes e danosas, bem como garantir a efetivação dos direitos fundamentas, com o direito dos trabalhadores locais de terem sua força de trabalho aproveitada.

Ora, tal conquista tem a possibilidade de auxiliar no desenvolvimento regional, na redução da migração (e no desenraizamento afetivo daquele que se afasta de seu meio social), e na redução dos impactos que essas migrações podem causar na comunidade local, mas, sobretudo, se apresenta como 
possibilidade de promover, como intervenção inicial, o acesso dessa população local na participação do mercado de trabalho, o fomento ao exercício da cidadania ativa e participante e à dignidade humana.

Além disso, essa participação no mercado local de trabalho visa contribuir para diminuir privações básicas e carências materiais da comunidade, possibilitando, inclusive, a busca por acesso aos serviços públicos essenciais, além de fortalecer laços afetivos que a pobreza e a miséria podem, por vezes, anuviar.

\section{A MIGRAÇÃO E SUAS MAZELAS}

Desta feita, a preocupação para que haja contratação de trabalhadores locais em percentual cada vez mais elevado, em vez da contratação de trabalhadores oriundos de outros lugares, vai ao encontro do desenvolvimento responsável da região, e o mais importante, facilita o respeito às normas internacionais, constitucionais e infraconstitucionais de proteção ao trabalhador.

Não obstante ao que foi dito, mesmo que seja garantido um percentual para contratação de mão de obra local nos empreendimentos de grande vulto, certamente, ainda assim haverá uma quantidade de trabalhadores que possam vir oriundos de outras regiões do país, ou seja, trabalhadores migrantes. Nesta senda, é patente que junto à migração pode estar atrelado o trabalho precário, informal ou até mesmo em situação análoga à de escravo.

Com fulcro na temática de combate e prevenção ao trabalho escravo, o Observatório Digital do Trabalho Escravo no Brasil monitora os dados que são obtidos após as ações de resgate de trabalhadores e trabalhadoras que se encontravam nessa situação degradante.

Por meio desse importante instrumento, verificou-se que, em sua grande maioria, os resgatados estavam trabalhando em locais distintos de sua origem ou do local de sua residência, ou seja, eram migrantes. Os resultados obtidos durante o período de 2003 a 2007 contam com mais de 43.000 resgates (ODTEB, 2017). A imagem abaixo aponta um exemplo dos locais no Brasil onde houve maior frequência de resgate:

Imagem 1 - Mapa que aponta os locais de maior incidência no Brasil de resgate de trabalhadores em situação análoga a de escravo, no período de 2003 a 2007:

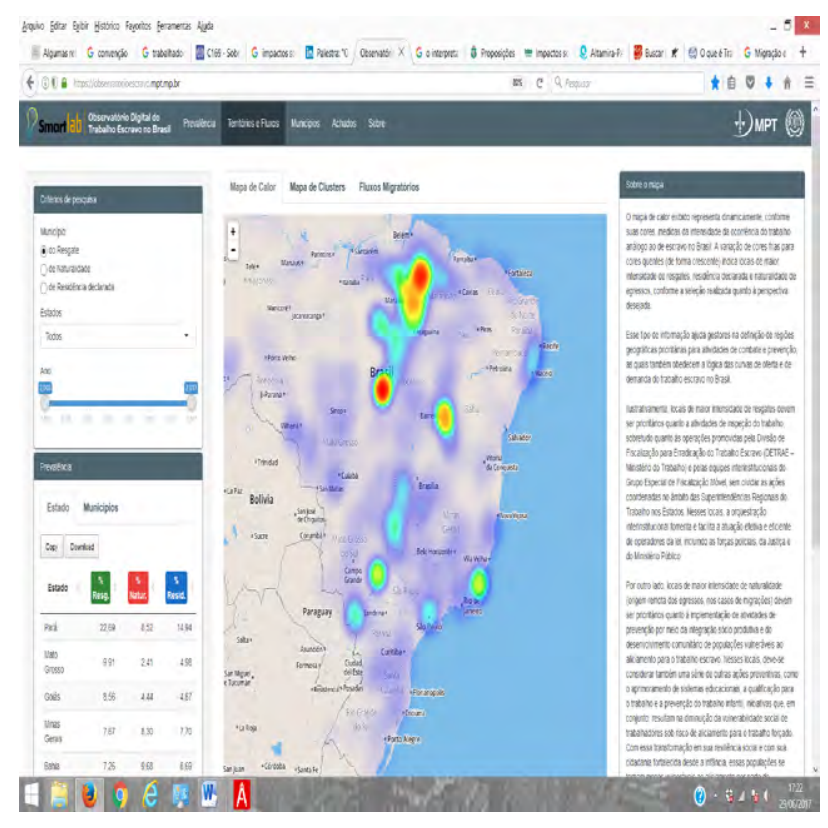

Fonte: (ODTEB, 2017). 
Os números apontados e a imagem são capazes ratificar que onde há migração, também há grandes interferências sociais, econômicas, ambientais e culturais. Esta é causadora de severo impacto social, seja para a comunidade recebedora dessa migração, seja devido ao vácuo das ausências no local de origem, seja para o próprio trabalhador que deixa suas raízes emocionais, sociais e afetivas em busca de trabalho.

Esse desenraizamento do trabalhador de seu seio social, de sua cultura, de sua identidade afetiva tem um efeito psíquico sobre ele. Hélia Borges e André Martins (2004, p. 132) apontam que:

Podemos dizer que, em termos psíquicos, o movimento migratório implica a noção de fragmentação de uma identidade. Ao se deixar um território, necessariamente entra em jogo a perda dos referenciais conhecidos. O processo de separação gera uma experiência de desamparo que na maioria das vezes é vivida como abandono. (grifo nosso)

Nesse sentido, para que a migração e os deslocamentos internos de trabalhadores não causem danos severos a eles próprios e à comunidade destino, como os exemplificados neste trabalho, é necessário que haja um projeto socioambiental que monitore, ordene, e seja responsável pela qualidade de vida destes trabalhadores, principalmente levando em consideração as proposições da comunidade envolvida.

Assim, também se estará atendendo ao Objetivo 10 da Agenda 2030, quando trata da redução das desigualdades nos países, que prescreve que deve se "facilitar a migração e a mobilidade ordenada, segura, regular e responsável das pessoas, inclusive por meio da implementação de políticas de migração planejadas e bem geridas" (ONU, 2015).

Diante do que foi dito, verifica-se que em decorrência da instalação de obra de grande vulto vários impactos socioambientais são possíveis de acontecer, e, certamente, irão. No entanto, estes podem ser minimizados, mediante a realização prévia de estudos sociais e ambientais, bem como o respeito ao direito de consulta prévia das populações envolvidas.

O direito de consulta prévia não se confunde com o direito de sufrágio ou com o direito de participar de audiências públicas, mas se firma como um direito de ser consultado previamente e de participar livremente na adoção das decisões que possam atingi-los, ou seja, de ter voz efetiva, audível e de ter vez na condução dos assuntos de seus interesses.

Nesse sentido, sem que seja feito um estudo aprofundado dos impactos ambientais e sociais passíveis, e sem que seja oportunizada consulta prévia à população interessada para que esta possa colaborar no estabelecimento de condicionantes e regramentos, resta patente que os problemas que acompanham as obras de grande vulto são capazes de minar o desenvolvimento e as liberdades subjetivas dos envolvidos, como as mazelas da migração desordenada, por exemplo.

\section{AS OBRAS DE GRANDE IMPACTO SOCIOAMBIENTAL, A PARTICIPAÇÃO LOCAL E O DESENVOLVIMENTO SUSTENTÁVEL}

As obras de grande impacto podem ser necessárias e se mostram atreladas ao desenvolvimento econômico do país, mas, como bem delineado, se feita sem um planejamento ou um projeto socioambiental adequado, responsável e mediante a participação efetiva da comunidade envolvida, distancia-se da materialização do desenvolvimento sustentável.

Não basta a preocupação com a migração sem controle de trabalhadores, é necessário também que as grandes obras - e seus impactos - causem o menor dano possível à vida das comunidades em seu entorno, e, sobremaneira, não degradem o meio ambiente a ponto de por em risco as futuras gerações.

É necessário que o desenvolvimento econômico a ser obtido com a obra coexista com o conceito de sustentabilidade, sob pena de se tornar inviável. 
Essa percepção da transformação do mundo sob o conceito de desenvolvimento sustentável é a pauta da Agenda 2030 da Organização das Nações Unidas (ONU). Pensar o planeta para as pessoas e para a prosperidade em uma parceria colaborativa é o fundamento dos seus 17 Objetivos.

A sustentabilidade se apresenta em vários dos Objetivos da Agenda 2030 (ONU, 2015), como por exemplo:

\begin{abstract}
11.a Apoiar relações econômicas, sociais e ambientais positivas entre áreas urbanas, periurbanas e rurais, reforçando o planejamento nacional e regional de desenvolvimento. 12.6 Incentivar as empresas, especialmente as empresas grandes e transnacionais, a adotar práticas sustentáveis e a integrar informações de sustentabilidade em seu ciclo de relatórios. (ONU, 2015)
\end{abstract}

Nesse sentido, sustentabilidade seria, portanto, "[...] uma palavra-chave na busca de um novo sistema de valores, um novo paradigma civilizatório, [...], atende às necessidades do presente sem comprometer a capacidade das futuras gerações de atender às próprias necessidades. [...]" (TRIGUEIRO, 2012, p. 362).

Assim, da mesma forma que se defende o direito de consulta às comunidades locais para influenciar na estipulação do percentual de mão de obra local, quando da instalação de uma obra de grande vulto, também se faz necessário atrelar essa construção ao desenvolvimento sustentável da região.

Seu impacto e sua interferência não podem ser tão desmedidos a ponto de erradicar a vida natural (fauna, flora, mananciais etc), nem por em risco o modo de vida e a cultura das comunidades locais; há que se harmonizar com a sustentabilidade.

A importância do desenvolvimento sustentável foi objeto da Declaração do Rio de Janeiro (ONU, 1995) sobre o Meio Ambiente e Desenvolvimento de 1992, obtendo uma visibilidade internacional. Esta reafirmou o teor da Declaração da Conferência das Nações Unidas sobre o Meio ambiente Humano realizada em Estocolmo no ano de 1972, e, avançando, estabeleceu novas parcerias e acordos de cooperação visando o respeito à integridade do meio ambiente e o desenvolvimento em amplitude global, culminando na sustentabilidade.

Outro instrumento inspirador foi o chamado Relatório de Brundtland que utilizou a expressão "Desenvolvimento Sustentável". Nele há a fundamental relação entre crescimento e necessidade humana: [...] O desenvolvimento sustentável requer que as sociedades atendam às necessidades humanas tanto pelo aumento do potencial produtivo como pela garantia de oportunidades iguais para todos." (ONU, 2017)

Portanto, desenvolvimento sustentável decorre dessa associação e possui um valor ao mesmo tempo intrínseco e instrumental no tocante à promoção do desenvolvimento econômico de cunho acautelatório.

A Conferência de Joanesburgo (Rio+10), realizada em 2002, relativizando, ressignificando e reinventando a visão que se tinha sobre a componente ambiental dominante até aqui, realçou uma visão de sustentabilidade traduzida nas seguintes dimensões: viabilidade econômica, preservação ambiental e coesão social (HARRIS, 2001).

Dessa forma, a sustentabilidade - nessa visão tridimensional - pode ser compreendida sob a ótica do ecodesenvolvimento, ou seja, um desenvolvimento para além do simples crescimento econômico, pautado também no desenvolvimento social, ou seja, sob um viés que se firma pela satisfação das necessidades, mas com foco na utilização racional (SACHS, 1980) (SACHS, 1986) e controlada dos recursos existentes; da cautela com os desperdícios e contra a degradação ambiental, o que, por conseguinte, também representa o respeito ao desenvolvimento dos povos.

Ainda nessa toada, Sandrina Moreira aponta que a preocupação com o desenvolvimento sustentável tem a ver com a atenção que deve ser dada à disponibilidade dos recursos naturais para as futuras gerações, sob a ótica da solidariedade intergeracional (MOREIRA, 2012). É preciso desenvolver a consciência da utilização dos recursos (renováveis ou não) e dos seus limites. E, a nosso ver, essa mesma preocupação deve ser tida com a cultura e o modo de vida dos povos tradicionais e das comunidades. 
A preocupação com a vida que se leva a proteção da cultura, do meio ambiente e a garantia dessa proteção para as gerações futuras fundamenta esse direito de participação e de desenvolvimento sustentável local.

Há uma nova relação com a natureza pautada na interdependência sistêmica, adotando uma lógica de cautela e de contenção impondo um ritmo sustentável de equilíbrio entre a "entrada de", o "processamento de" e a "saída de", representando uma corrida de fundo e não de velocidade na interação entre economia e a ecologia, como aponta Amaro (AMARO, 2003).

Um desenvolvimento que deve objetivar a satisfação das principais necessidades de todos, mas também estender a todos a oportunidade de aspirar uma vida melhor. Assim, um desenvolvimento que se sustenta em dois alicerces, conforme Thomas Davis: a utilização dos recursos e a consciência que estes têm finitude e são limitados, como, por exemplo, o uso sustentável dos recursos que não utilizados na produção e no consumo (DAVIS, 2017).

Desenvolvimento que se sustenta em três importantes pilares, de acordo com Sandrina Moreira:

[...] (i) auscultação das necessidades das populações; (ii) mobilização das capacidades locais como ponto de partida para as respostas; (iii) visão integrada dos problemas e soluções. Uma multiplicidade de formulações seguiu-se à concepção alternativa do desenvolvimento comunitário e desembocaram no conceito de desenvolvimento local. (MOREIRA, 2012)

Assim, sustentabilidade pautada na busca por uma vida melhor, esta como um componente do desenvolvimento, requer a participação ativa das comunidades locais na resolução de seus problemas e igualmente na valorização dos recursos locais, por isso a utilização do direito de consulta garantido pela Convenção 169 da OIT, na forma como posta neste artigo.

Nesse sentido, o desenvolvimento sustentável requer a participação da base comunitária, pois os envolvidos conhecem os recursos naturais e os elementos da cultura local, sendo fundamental sua manifestação para apontar as necessidades prioritárias da comunidade e articular em busca desse atendimento. É o que Pecqueur denomina de "desenvolvimento local", uma lógica participativa que valoriza a participação da comunidade local na resolução de seus problemas, respeito aos recursos locais e sua identidade, reforçando seu empoderamento e capacidade (PECQUER, 1990, p. 53-55).

Dessa forma, aliando a participação ativa da comunidade, o respeito aos recursos naturais e a manutenção de sua identidade cultural, chega-se ao desenvolvimento participativo que representa a luta por voz e vez em busca do desenvolvimento sustentável. Conteúdo que resulta em um desenvolvimento centrado nas pessoas ao invés de um desenvolvimento apenas centrado nos bens, conforme a doutrina de Friedmann e Korten (1992).

\section{A CONVENÇÃO 169 DA OIT E O DIREITO DE CONSULTA PRÉVIA: A APLICAÇÃO DESSE DIREITO PARA ALÉM DOS POVOS INDÍGENAS COMO DIREITO FUNDAMENTAL DAS COMUNIDADES NA DEFESA DE SEUS INTERESSES}

Ante ao que segue posto, é importante que a população diretamente impactada com a instalação de um projeto de grande vulto tenha o direito fundamental de ser previamente ouvida, consultada e que suas colocações sejam levadas em consideração, como a oportunizada pela Convenção 169 da OIT (OIT, 1989).

A Convenção 169 da OIT, ratificada pelo Brasil por meio do Decreto 5.051/2004 (BRASIL, 2004), fundada na prevenção da discriminação, é um instrumento que busca efetivar o respeito às formas de vida, ao desenvolvimento econômico, às identidades, línguas e religiões dos povos indígenas e tribais. Seu objetivo é realizar a inclusão social de aproximadamente 40 milhões (OIT,2013) de pessoas que têm sido negligenciadas em toda a América Latina. 
Além do conteúdo que versa sobre essa política geral, traz um importante elemento de participação democrática, que é o direito de consulta prévia constante do art. 6o, como garantia de participação ativa desses povos nos processos decisórios que os afetam. Consulta e participação é o enfoque deste Convênio que, por meio de acordos e consensos, visa soluções conjuntas que seguem na direção do desenvolvimento das liberdades dos povos interessados.

As obras e empreendimentos de grande monta, todas, sob o fundamento do aumento do crescimento econômico e do desenvolvimento do país, chegam e se instalam, porém, curiosamente, nunca (ou quase nunca) são submetidas ao crivo da população diretamente impactada, mediante processos democráticos e efetivos de consulta prévia. Esses processos precisam ser ressignificados e a população interessada deve ser ouvida, ter o poder de influenciar nas ações e decisões que vierem a ser tomadas em todas as fases, e esse direito deve ser respeitado.

Esse direito se revela quando se oportuniza às comunidades o direito de consulta adequada e antes que as autoridades públicas tomem as decisões que possam afetá-las, como por exemplo, aquelas que envolvam a exploração dos recursos naturais, a realização de obras de infraestrutura, esboço de planos de desenvolvimento.

Sendo a consulta prévia um "requisito procedimental que deva ser cumprido necessariamente antes da tomada de decisões, sua falta de cumprimento determina a invalidez das medidas tomadas sem respeitar a exigência de consulta. [...]" (COURTIS, 2009). É essa exigência, bem como a vinculação das decisões acordadas que ressaltam o diferencial da Convenção 169 da OIT em detrimento dos demais instrumentos de participação popular.

Ademais, o estímulo e o respeito à participação incentiva naturalmente a formação de lideranças, inclusive favorecendo a participação da liderança feminina nas comunidades, o que atende ao Objetivo 5 da Agenda 2030, que em seu item "5.5" estabelece a garantia da participação plena e efetiva das mulheres e a igualdade de oportunidades para a liderança em todos os níveis de tomada de decisão na vida política, econômica e pública (ONU, 2015).

Por isso, as comunidades devem, previamente, e em tempo adequado, ter ciência dos planos e projetos que se delineiam, e assim poderem se organizar, formular opiniões, sugerir regramentos, condicionantes e contrapropostas de forma livre e sem pressões. Além disso, o resultado da consulta deve ser levado em consideração quando da decisão final do projeto que vier a se materializar.

Esse instrumento, não obstante seja um direito voltado para os povos indígenas e tribais, se apresenta como um importante princípio democrático que garante o direito à consulta prévia, e que, justamente por isso, é aqui defendido como possível de ser estendido à população que se encontra em vias de ser impactada por grandes empreendimentos, ou seja, ser estendido às comunidades locais e tradicionais.

A Corte Interamericana de Direitos Humanos (CIDH) no julgamento do caso do Povo Saramaka Vs. Suriname, decidiu pela garantida a aplicação da Convenção 169 da OIT a uma comunidade quilombola, o que representa, na prática, a extensão da aplicação da norma:

[...] A análise anterior sustenta uma interpretação do artigo 21 da Convenção Americana no sentido de reconhecer o direito dos integrantes dos povos indígenas e tribais a que determinem e gozem livremente de seu próprio desenvolvimento social, cultural e econômico, o que inclui o direito a gozar da particular relação espiritual com o território que tradicionalmente usaram e ocuparam. Por isso, no presente caso, o direito à propriedade protegido no artigo 21 da Convenção Americana e interpretado à luz dos direitos reconhecidos nos artigos $1^{\circ}$ comum e 27 do PIDCP, os quais não poderão ser restringidos ao interpretar-se a Convenção Americana no presente caso, confere aos integrantes do povo Saramaka o direito ao gozo de sua propriedade de acordo com sua tradição comunitária. No presente caso o Estado não garantiu, com antecedência, a participação efetiva do povo Saramaka, através de seus métodos tradicionais de tomada de decisão [...]. Tal como foi mencionado anteriormente, a questão não é se o Estado deve consultar os Saramaka, mas se, de fato, o Estado também deve obter seu consentimento. (CIDH, 2007) (grifo nosso) 
Da mesma forma é o que se defende nesse artigo, ou seja, a aplicação da Convenção - o direito de consulta - para as comunidades pequenas, pois devido ao seu isolamento ou até distanciamento dos grandes centros, possuem as mesmas peculiaridades que as comunidades quilombolas, indígenas e tribais. A realidade em que vivem as tornam similares.

Essa população impactada não está longe de ser considerada como uma comunidade tradicional e que, igualmente aos índios, quilombolas e povos de matrizes africanas, devem ser ouvidas previamente, ou seja, antes de ter uma obra de grande vulto instalada em sua região.

Geralmente, são comunidades - organizadas ou não - que vivem em áreas rurais ou que estão localizadas distantes dos grandes ou médios centros urbanos e que podem ser formadas por seringueiros, pescadores artesanais, marisqueiras, ribeirinhos, sertanejos, catingueiros, jangadeiros, caiçaras, pantaneiros, castanheiros, pequenos agricultores, artesãos e todos aqueles que vivem em pequenos povoados ou municípios e que são diretamente impactados pelos grandes empreendimentos e que podem ter seu modo de vida, cultura, tradição e laços afetivos afetados.

No mesmo sentido da amplitude do conceito protetivo da norma que se vem defendendo nesse trabalho, é colocação de DUPRAT (2012, p.66):

A Convenção n. 169, no Brasil, se aplica a todos esses grupos e a tantos outros que se apresentem sob o único vetor que normativamente os aproxima: organização social, política e cultural distinta das sociedades de grande formato. São muitos, sim. O direito apenas os inviabilizou por longo tempo. Chegou a hora de conhece-los e reconhece-los como sujeitos de direitos. E, por isso, é preciso convidá-los a falar [...] (grifo nosso)

Tais empreendimentos são aptos a afetar os direitos, a cultura, a diversidade e os modos de vida dessa população, principalmente no tocante ao direito de acesso ao emprego.

Nesse sentido, por entendermos que tal norma, traz a igualdade de tratamento e de oportunidade, o direito a não discriminação, bem como o exercício dos direitos humanos (OIT, 1989), defende-se aqui que esta deve ser reconhecida para além dos povos indígenas e tribais, sendo estendida a todos aqueles que necessitem utilizar de seu conteúdo normativo para a garantia do exercício de seus direitos fundamentais, da dignidade e para a expansão de suas liberdades subjetivas, materializado por meio da consulta prévia prevista na Convenção no 169 da OIT.

COURTIS (2009) ao apontar a influência da Convenção nos países da América Latina e sua influência na legislação interna, registra que esta foi empregada e invocada pelas próprias comunidades e povos indígenas, mas, não só, sua aplicação também foi utilizada como instrumento ou padrão interpretativo de outras normas.

Não se está aqui indo contra os avanços da modernidade e tecnologia, mas em busca de garantir às comunidades diretamente impactadas por decisões que possam interferir em suas vidas - como é o caso de obras de grande vulto - a utilização de um instrumento real de liberdade de expressão.

Assim, a consulta prévia e adequada, ou seja, por meio de uma linguagem que permita a compreensão do projeto pela comunidade envolvida é um importante instrumento de tomada de decisão de cunho democrático. Acerca do instrumento da consulta prévia, DUPRAT (2012, p. 68) afirma que:

[...] antes de iniciado o processo decisório, as partes se colocam em um diálogo que permita, por meio de revisão de suas posições iniciais, chegar à melhor decisão. Desse modo, a consulta traz em si, ontologicamente, a possibilidade de revisão do projeto inicial ou mesmo de sua não realização.

De acordo com YAMADA; OLIVEIRA (2013, p. 13) "A consulta é um processo de diálogo, de conversas justas e de boa-fé que garante a participação dos povos diretamente afetados, respeitando suas particularidades culturais, seu jeito e seus planos de vida e de futuro.", portanto, atendendo ao que aqui se propõe, que é o direito da comunidade afetada ser levada em consideração e com prioridade no percentual 
de vagas em obras de grande vulto.

Há palavras, frases e termos, que, extraídos dos artigos da Convenção (OIT, 1989), saltam aos olhos como necessários e inerentes ao exercício dos direitos fundamentais, tais como: "consciência de sua identidade" (art. 1ํ, "2"), "participação os interessados" (art. 2º, "1"), "consultar os interessados", "possam participar livremente" (art. 6o, "1", “a”), "direito de escolher suas, próprias prioridades", "participar da formulação, aplicação e avaliação dos planos e programas de desenvolvimento nacional e regional suscetíveis de afetá-los diretamente" (art. 7,"1") e "proteção eficaz em matéria de contratação e condições de emprego" (art.20, "1").

Todas as expressões acima colacionados relacionam-se com o despertar da consciência das pessoas de que seus interesses são, na verdade, os interesses de toda comunidade e que devem ser respeitados, por exemplo, por meio do direito de participação nas decisões que impactam em suas vidas, de serem consultados previamente.

É esse sentimento de coesão, essa "liga", essa autodeterminação quanto ao pertencimento a um grupo, a uma cultura e a um modo de vida que justifica a aplicação da Convenção 169 para além dos povos indígenas e tribais, mas que possuem características próprias que se assemelham a estas, portanto, também detentoras do direito de serem consultadas previamente ante decisões geradoras de impacto em suas vidas.

Nesse sentido, vê-se no conteúdo da Convenção um viés pautado pelo exercício da cidadania, esta, concebida, ativamente, como a participação de seus titulares na sociedade. Portanto, da mesma forma que a cidadania é um direito fundamental, o conteúdo convencional, recheado de direitos humanos, também o é, e, assim sendo, deve ser usufruído por todos.

Daí o teor dessa Convenção - direito de consulta prévia - ser imprescindível para a efetivação dos direitos fundamentais de um povo, como o direito de acesso ao emprego e renda em condições prioritárias em relação à mão de obra migrante, portanto, não deve ser restrita somente aos povos indígenas e tribais, principalmente, porque prega a não discriminação e a efetivação da cidadania enquanto democracia participativa.

Por fim, tem-se ciência de que o teor da Convenção significou uma grande conquista para os povos indígenas e tribais, notadamente porque busca garantir o respeito à diversidade cultural dos povos envolvidos, e o reconhecimento de suas identidades, não sendo intenção desse estudo fragiliza-la, mas, ao contrário, torná-la um instrumento para - no que couber - ser utilizado pela população que se encontra em vias de sofrer lesões socioambientais profundas, como meio eficaz e democrático de exercício da cidadania.

Dessa forma, por ser o direito de consulta prévia um elemento sólido de efetiva participação na garantia e no respeito aos interesses de um povo - até mais célere, direto e concreto do que os demais processos de participação popular -, que se ousou defender nesse trabalho a extensão desses direitos às comunidades que são impactadas por obras de grande vulto, independentemente se se enquadram nos povos objeto do Convênio, principalmente porque não são levadas em conta no planejamento e na elaboração dos projetos que impactam em suas vidas.

Martin Scheinin (2005, p.16) destaca a importância do direito de participação para todos aqueles que se encontram numa situação, igualmente aos povos indígenas, de despojamento de seus direitos, porém defende que se faz necessário uma clareza analítica sobre o conceito de "povos", principalmente porque só a estes está atrelada a possibilidade de autodeterminação:

Qual é o senso de tudo isso? Não é divisivo e destrutivo construir linhas de separação dentro do movimento mundial unido dos povos indígenas? Não há muita sabedoria na abordagem representada pelo Projeto de Declaração de não "definir" os povos indígenas, mas sim tomar uma abordagem pragmática de aceitar no movimento todos os grupos que estão igualmente situados em termos de serem despojados através da colonização ou outros históricos eventos? Não são iguais todos os povos, por exemplo em relação ao direito à autodeterminação? Na minha opinião, faz sentido lutar pela clareza analítica. [...]. Quanto à igualdade de todos os povos, a minha resposta é que sim, de fato, todos 
os povos são iguais e têm direito ao direito à autodeterminação. Mas essa igualdade só fortalece o argumento para a necessidade de fazer uma distinção entre povos e "pessoas", pois apenas os primeiros gozam do direito à autodeterminação. Permitir que todas as minorias e grupos indígenas autoproclamados para saltar no movimento do Projeto de Declaração prejudiquem a credibilidade do artigo 3 do Projeto, de acordo com o qual "os povos indígenas têm o direito de autodeterminação". Para que o direito da autodeterminação seja reconhecido, os povos indígenas terão que aceitar que ser indígena não traz automaticamente com ele ser "um povo".

Assim, tais comunidades - igualmente aos povos indígenas e tribais -, também têm sua cultura, seus costumes, seus modos de vida e seus direitos ceifados devido aos impactos que as grandes obras e grandes empreendimentos deixam em suas vidas (individual e coletiva).

\section{O DIREITO DE CONSULTA PRÉVIA COMO UM DIREITO FUNDAMENTAL}

Diante do que se apresenta nesse trabalho, a parte da Convenção 169 da OIT que versa sobre o direito de consulta prévia, livre e informada garante a cidadania e o exercício da democracia, portanto, é um direito fundamental.

A sua temática é inspiradora e se vê seu alcance interpretativo em diversos tipos de ações que envolvem interesses dos povos indígenas e tribais. Courtis (2009, p. 59) exemplifica:

[...] a Convenção 169 foi invocada em ações de inconstitucionalidade, em ações de amparo ou tutela constitucional, em controvérsias entre poderes, em ações políticoeleitorais, em ações de nulidade em matéria contencioso-administrativa, em ações civis ordinárias (nas quais são discutidos assuntos de propriedade ou despejo, por exemplo), em ações penais, em ações que tramitam no foro agrário, entre outras [...].

No Poder Judiciário brasileiro também se vê demandas e decisões que mostram a importância do direito de consulta insculpido na Convenção, tanto que, se não observado, pode macular todo o projeto de grande vulto embargando-o ou o considerando nulo, desde seu início, a título de exemplo o pedido constante da Apelação Cível no 2006.39.03.00o711-8/PA, objeto de apreciação pelo TRF da ıª Região:

[...] buscou-se a concessão de provimento judicial, consistente na imposição ao Instituto Brasileiro do Meio Ambiente e dos Recursos Naturais Renováveis - IBAMA, no sentido de que se abstenha de editar qualquer ato administrativo relativo ao licenciamento ambiental em referência, amparando-se nos seguintes fundamentos:

a) Vício material do processo legislativo que deu origem ao Decreto Legislativo 788/2005, por ausência de consulta prévia, às comunidades indígenas afetadas, nos termos do art. 231, §3º da CF/88 e do art. 6o, 1, a, da Convenção 169 da OIT, ratificada pelo Brasil, através do Decreto Legislativo 143/2002. [...]. (TRF-1 - AC: 259997520104013900 PA 0025999-75.2010.4.01.3900, Relator: DESEMBARGADOR FEDERAL SOUZA PRUDENTE, Data de Julgamento: 26/03/2014, QUINTA TURMA, Data de Publicação: e-DJF1 p.36o de 22/04/2014). (BRASIL, 2014) (grifo do autor)

No entanto, o objeto do presente estudo, ou seja, a extensão do direito de consulta prévia, livre, e informada constante da Convenção no 169 da OIT como mais um elemento de direito a ser utilizada pela população diretamente afetada pelas obras e empreendimentos de grande vulto, notadamente, a estipulação de percentual de reserva de vagas de emprego para o trabalhador (e trabalhadora) local, é maculado se não tiver um arcabouço no Direito que possa fazer com que o conteúdo da Convenção seja aplicado de forma extensiva, para além daqueles os quais a norma - se considerada apenas como regra expressamente se dirige (povos indígenas e tribais).

Como bem-dito ao longo do estudo, não se está negando a existência de manifestação popular no 
Direito brasileiro, elas existem tanto na constituição (referendo, plebiscito, ação popular), como em normas infraconstitucionais (audiências públicas, conferências, mesas de debate etc.). No entanto, as decisões a partir desse exercício muitas vezes são desconsideradas pelos gestores, gerando um esvaziamento moral de seu significado para a democracia. A Lei no 9.709/98 (BRASIL, 1998) não entra nessa seara da vinculação, exceto no tocante a alteração territorial (art. $4^{\circ}, \S^{\circ} 1^{\circ}$ ).

No entanto, a força moral principiológica enraizada na Convenção sobre o direito fundamental de não discriminação e de reconhecimento da identidade dos povos, materializado pelo direito de consulta, tem um significado de garantia e proteção que transcende a discricionariedade do regramento lá posto.

Assim, sob o fundamento do direito de consulta prévia ser um direito fundamental de participação das comunidades locais envolvidas e sob iminente impacto de uma obra de grande vulto, se vê justificada a defesa de sua aplicação extensiva.

A teoria de Dworkin (2016) é um fundamento que corrobora a extensão da aplicação da Convenção no 169 da OIT para além dos povos indígenas e tribais, pois, se se fizer uma interpretação meramente positiva da norma (na medida em que limita o direito dos indivíduos ao que está previsto na norma), dela não se extrai nenhuma solução para o que se defende aqui.

Nesse sentido, a situação que busca a aplicação do art. 6o da Convenção pode, em uma demanda prática e devido a sua complexidade, não ser deferida por ser tida pelo intérprete ou julgador (com viés positivista) como não tendo uma regra identificável (com o pedido feito pela parte) para ser aplicada. Tal decisão, inclusive, poderia se mostrar com carência de fundamentação, transformando-se num ato apenas discricionário do juiz.

O objeto do presente estudo é apto a fomentar dúvida e até certa complexidade num caso posto sob julgamento, pois numa colisão de direitos algumas dúvidas ou premissas poderiam surgir: a) a Convenção 169 da OIT é um direito somente direcionado aos povos indígenas e tribais ou seu conteúdo é de interpretação extensiva? b) seus princípios voltados para a auto identificação, não discriminação, especificidades culturais etc. são específicos ao direito de reconhecimento desses povos? c) populações outras (locais, tradicionais) na iminência de sofrer um impacto em suas vidas também podem se utilizar do instrumento de consulta prévia previsto na Convenção?

Porém, essas possíveis colisões podem ser desconstruídas quando se verifica que o conteúdo moral do direito de consulta prévia tem uma relação de peso com a democracia participativa. Ora, já dito nesse estudo, que não se nega a existência de outros meios de participação. Porém, nenhum tem um arcabouço principiológico de desenvolvimento coletivo e de cidadania participativa como este.

Assim, a interpretação necessária que se defende nesse estudo - a extensão do objeto da norma convencional para outros personagens não previstos por ela - não é pautada no conceito positivo de direito, mas também na visão dworkiniana de um dever legal de se analisar as demandas postas em confronto com as normas de uma forma mais holística e oferecendo critérios mais objetivos do que a discricionariedade, alcançando, inclusive, os princípios não convencionais. Seja esse princípio sob o argumento político, seja no próprio significado de princípio.

Dwokin (2016, p. 36), versando sobre os princípios, aponta que utiliza esses dois termos, em regra, como sinônimos, mas que em alguns casos os aplicará de forma distinta, cujo conteúdo aqui se transcreve:

[...] Denomino "política" aquele tipo de padrão que estabelece um objetivo a ser alcançado, em geral uma melhoria em algum aspecto econômico, político ou social da comunidade [...]. Denomino "princípio" um padrão a ser observado, [...], mas porque é uma exigência de justiça ou equidade ou alguma outra dimensão da moralidade [...].

Nesse sentido, essa dupla interpretação dos sentidos dos princípios dá a tônica à interpretação extensiva e coerente com o "pano de fundo" da demanda posta sob análise (legislativa, administrativa ou judicial), independentemente de o objeto da Convenção ser uma regra ou princípio. 
Não obstante a Convenção 169 da OIT não ter sido introduzida no ordenamento brasileiro por meio do rito estabelecido no parágrafo terceiro do art. $5^{\circ} \mathrm{da} \mathrm{CF} / 88$, é uma norma que possui um status supralegal.

Assim, mesmo que seja considerada uma regra, devido à existência de termos que possuem peso e importância moral, deverá, no caso concreto, ser interpretada como princípio, pois sua importância se mostra pelo seu peso moral, portanto, devendo ser aplicada para além dos povos indígenas e tribais, ampliando o efetivo direito de consulta prévia.

\section{CONSIDERAÇÕES FINAIS}

Ante a todo o exposto, resta comprovado a importância que o direito de consulta prévia constante do art. 6o da Convenção 169 da OIT tem para a efetivação da democracia participativa, pois o conteúdo de moral coletiva que está insculpido em tal norma traz elementos que nenhum outro instrumento de participação popular garante.

Participação ativa e empoderada das comunidades que se apresenta atrelada ao conteúdo do desenvolvimento sustentável, consciente e que leva em consideração tanto as necessidades prioritárias dos envolvidos como também a ideia de que os recursos naturais (renováveis ou não) são limitados, representando um compromisso de política social que colabora com os Objetivos da Agenda 2030 da ONU.

Não discriminação, reconhecimento da identidade cultural, modo de vida, empoderamento coletivo, auto-organização, são extraídos do conteúdo da Convenção sem nenhuma dificuldade, representando um desenvolvimento sustentável e participativo, principalmente se se levar em consideração o conceito de Direito a partir da doutrina de Dworkin.

Do contrário, o surgimento de um pleito fundado no direito de consulta previsto no art. 60 da Convenção da OIT feito por uma comunidade afetada por obras de grande vulto, que não faça parte do rol dos beneficiados da norma (povos indígenas e tribais), certamente no momento do julgamento - numa decisão fundada no positivismo jurídico -, não encontraria solução na norma, tendo que ser decidido de forma discricionária. O que resultaria, provavelmente, num indeferimento.

Também, não se vislumbrou que a aplicação estendida desse direito àqueles que não são por ela fixados possa enfraquecer a luta dos povos indígenas e tribais, visto que o direito de consulta prévia, livre e informada tem um conteúdo de moral coletiva apto a ser utilizado como instrumento de efetiva democracia participativa, podendo ser utilizado por todos aqueles afetados por obras de grande impacto socioambiental, pois sua identidade, modo de vida e os recursos naturais também estariam em risco.

No tocante à estipulação de percentual para contratação de trabalhadores locais, verificou-se que este é um elemento significante no desenvolvimento socioambiental das comunidades afetadas pelas obras de grande vulto, pois comprovado que junto com a migração volumosa de trabalhadores do sexo masculino, chegam mazelas de igual monta. Portanto, sua materialização por meio do instrumento de consulta prévia nos moldes de importância e efetividade previsto no art. 6o da Convenção 169 da OIT tem o condão de minimizar tais impactos e promover o desenvolvimento das liberdades e capacidades individuais e coletivas da população envolvida.

\section{REFERÊNCIAS}

AMARO, R. Desenvolvimento: Um conceito ultrapassado ou em renovação? Da teoria à prática e da prática à teoria. Cadernos de Estudos Africanos, 4, 2003. Disponível em: <http://revistas.rcaap.pt/cea/article/ view/8659/6214>. Acesso em: 12 nov. 2017. 
BORGES, Hélia. MARTINS, André. Migração e Sofrimento Psíquico do Trabalhador da Construção Civil: uma Leitura Psicanalítica. PHYSIS: Rev. Saúde Coletiva, Rio de Janeiro, n. 14, p. 129- 146, 2004. Disponível em: <http://www.scielo.br/pdf/physis/v14ni/v14nıao8.pdf>. Acesso em: 28 jun. 2017.

BRASIL. Lei $\mathbf{n}^{\circ} \mathbf{6 . 0 4 0 / 2 0 0 7}$, de o7 de fevereiro de 2007. Institui a Política Nacional de Desenvolvimento Sustentável dos Povos e Comunidades Tradicionais. Diário Oficial da República Federativa do Brasil. Poder Executivo, Brasília, DF, 8 fev. 2007. Disponível em:<http://www.planalto.gov.br/ccivil_03/_ato20072010/2007/decreto/d6040.htm> Acesso em: 10 out. 2017.

Lei $\mathbf{n}^{\circ}$ 5.051, de 05 de abril de 2004. Promulga a Convenção no 169 da Organização Internacional do Trabalho - OIT sobre Povos Indígenas e Tribais. Diário Oficial da República Federativa do Brasil. Poder Executivo, Brasília, DF, 20 abr. 2004. Disponível em: <http://www.planalto.gov.br/ccivil_03/_ ato2004-2006/2004/decreto/d5051.htm.> Acesso em: 10 out. 2017.

Lei $\mathbf{n}^{\circ} \mathbf{7 \cdot 7 4 6 / 2 0 1 2}$, de 05 de junho de 2012. Regulamenta o art. $3^{\circ}$ da Lei no -8.666 , de 21 de junho de 1993, para estabelecer critérios, práticas e diretrizes para a promoção do desenvolvimento nacional sustentável nas contratações realizadas pela administração pública federal, e institui a Comissão Interministerial de Sustentabilidade na Administração Pública - CISAP. Diário Oficial da República Federativa do Brasil. Poder Executivo, Brasília, DF, o6 jun. 2012. Disponível em: <http://www.planalto. gov.br/ccivil_03/_Ato2011-2014/2012/Decreto/D7746.htm.> Acesso em: 28 jun. 2017.

Lei no 9.709, de 18 de novembro de 1998. Regulamenta a execução do disposto nos incisos I, II e III do art. 14 da Constituição Federal. Decreto nº 6.040/2007. Brasília, DF, 19 nov. 1998. Diário Oficial da República Federativa do Brasil. Brasília, DF, 19 nov. 1998. Disponível em: <http://www.planalto.gov.br/ ccivil_03/leis/l9709.htm.> Acesso em: 18 abr. 1998.

Ministério do Planejamento Orçamento e Gestão. Instrução Normativa nº or de janeiro de 2010. Dispõe sobre os critérios de sustentabilidade ambiental na aquisição de bens, contratação de serviços ou obras pela Administração Pública Federal direta, autárquica e fundacional e dá outras providências. Poder Executivo, Brasília, DF, 19 jan. 2010. Disponível em: <http://www.comprasnet.gov.br/legislacao/ legislacaoDetalhe.asp?ctdCod=295 >. Acesso em: 28 jun. 2017.

Tribunal Regional Federal (1. Região). Apelação cível n. o025999-75.2010.4.01.3900/PA (25999752010401390o). Apelante: Ministério Público Federal. Apelado: Agência Nacional de Energia Elétrica- ANEEL e outros. Relator: Desembargador Federal Souza Prudente. Brasília, 26 de março de 2014. Disponível em: <https://trf-1.jusbrasil.com.br/jurisprudencia/25057536/apelacao-civel-ac2599975201040139oo-pa-0025999-75201040139oo-trfi/inteiro-teor-117939524\# >. Acesso em: 30 jun. 2017.

Poder Judiciário. Tribunal Superior do Trabalho. Secretaria de Comunicação Social. "Ministro do TST discute trabalho decente". In: Notícias do TST. 2013. Disponível em: <http://www.tst.jus.br/ web/guest/noticias-teste/-/asset_publisher/89Dk/content/tv-tst-ministro-do-tst-discute-trabalhodecente?redirect=http\% ${ }_{3} \mathrm{~A} \% 2 \mathrm{~F} \%{ }_{2} \mathrm{~F} \quad$ www.tst.gov.br\%2Fweb\%2Fguest $\% 2$ Fnoticiasteste\% ${ }_{3} \mathrm{Fp} \_\mathrm{p}$ id\%3D101_INSTANCE_89Dk\%26p_p_lifecycle\%3Do\%26p_p_state\%3Dnormal\%26p_p_ mode\%3Dview\%26p_p_col_id\%3Dcolumn-2\%26p_p_col_count\%3D2>. Acesso em: 28 jun. 2017.

CEARÁ. Poder Legislativo. Assembleia Legislativa. PL n 20/2017. Disponível em: <https://www2.al.ce. gov.br/legislativo/tramit2017/pl2o_17.htm>. Acesso em: 28 jun. 2017. 
CORTE INTERAMERICANA DE DIREITOS HUMANOS (CIDH). Caso do Povo Saramaka Vs. Suriname. 2007. Disponível em: <http://www.cnj.jus.br/files/conteudo/arquivo/2016/o4/ ccra1e511769096f84fb5effe768fe8c.pdf > . Acesso em: 24 out. 2017.

COURTIS, Christian. Anotações sobre a aplicação da convenção 169 da OIT sobre povos indígenas por tribunais da américa latina. SUR - Revista Internacional de Direitos Humanos. São Paulo.v. 6. n. 10. p. 5381, jun. 2009. Disponível em: http://www.scielo.br/scielo.php?pid=S180664452009000100004\&script=sci abstract\&tlng=pt >. Acesso em: 30 jun. 2017.

DAVIS, Thomas. What Is Sustainable Development? 2017. Disponível em: <http://geodesy.unr.edu/ hanspeterplag/library/projects/sustainability/www. menominee.edu-sdi-whatis.htm >. Acesso em: 13 nov. 2017.

DINO, Natália Albuquerque. Entre a Constituição e a Convenção 169 da OIT: o direito dos povos indígenas à participação social e à consulta prévia como uma exigência democrática. Boletim Científico ESMPU. Brasília, ano 13, n. 42-43, p. 481-520. jan./dez. 2014. Disponível em: <http://boletimcientifico.escola.mpu. mp.br/boletins/boletim-cientifico-n-42-43-janeiro-dezembro-2014/entre-a-constituicao-e-a-convencaon-169-da-oit-o-direito-dos-povos-indigenas-a-participacao-social-e-a-consulta-previa-como-umaexigencia-democratica>. Acesso em: 28 out. 2017.

DUPRAT, Deborah. Direito ao Desenvolvimento e Integração Regional. In: PAGLIARINI, Alexandre Coutinho. DIMOULIS, Dimitri (Coord.). Direito Constitucional Internacional dos Direitos Humanos. Belo Horizonte: Fórum, 2012.

DWORKIN, Ronald. Levando os direitos a sério. São Paulo: Martins Fontes, 2016.

FRIEDMANN, J. Empowerment: the politics of alternative development. Cambridge: Bl

KORTEN, D. People-centered development: alternative for a world in crisis. In: BAUZON, K. Development and democratization in the third world: myths, hopes and realities. New York: Crane Russak, 1992. ackwell, 1992.

GALVEZ, Camila. "Faltou prevenção antes e durante obras”. Jornal Diário do Grande ABC. 2011. Disponível em: <http://www.dgabc.com.br/Noticia/255892/faltou-prevencao-antes-e-durante-obras>. Acesso em: 28 jun. 2017.

GONÇALVES, Alfredo José. “Migrações internas: evoluções e desafios”. Instituto de Estudos Avançados da Universidade de São Paulo. 2001. Disponível em: <http://www.scielo.br/scielo.php?script=sci_ arttext\&pid=So103-40142001000300014>. Acesso em: 28 jun. 2017.

HARRIS, J. A Survey of Sustainable Development: Social and Economic Dimensions. Washington: Island Press, 2001.

INSTITUTO SOCIOAMBIENTAL (ISA). ISA retifica matéria sobre contratação de mão de obra local para Belo Monte. Disponível em: <https://site-antigo.socioambiental.org/nsa/detalhe?id=3639>. Acesso em: 28 jun. 2017. 
MOREIRA, Sandrina Berthault; CRESPO, Nuno. Economia do Desenvolvimento: das abordagens tradicionais aos novos conceitos de desenvolvimento. Revista de Economia, v. 38, n. 2 (ano 36), p. 25-50, maio/ago. 2012. Editora UFPR. Disponível em <http://revistas.ufpr.br/economia/article/view/29899>. Acesso em: 12 nov. 2017.

OBSERVATÓRIO DIGITAL DO TRABALHO ESCRAVO NO BRASIL (ODTEB). Smartlab de Trabalho Decente. MPT - OIT. 2017. Disponível em: <https://observatorioescravo.mpt.mp.br/>. Acesso em: 28 jun. 2017.

ORGANIZAÇÃO DAS NAÇÕES UNIDAS (ONU). Conferência das Nações Unidas Sobre o Meio Ambiente. Declaração do Rio de Janeiro sobre meio ambiente e desenvolvimento. 1995. Disponível em: <http:// www.onu.org.br/rio2o/img/2012/o1/agenda21.pdf>. Acesso em: 13 nov. 2017.

ORGANIZAÇÃO DAS NAÇÕES UNIDAS (ONU). A ONU e o meio ambiente. 2017. Disponível em: $<$ https://nacoesunidas.org/acao/meio-ambiente/>. Acesso em: 13 nov. 2017.

ORGANIZAÇÃO DAS NAÇÕES UNIDAS (ONU). Transformando nosso mundo: a agenda 2030 para o desenvolvimento sustentável. 2015. Disponível em: https://nacoesunidas.org/pos2015/agenda2030/. Acesso em: 12 nov. 2017.

ORGANIZAÇÃO INTERNACIONAL DO TRABALHO (OIT). Convenção n. 169. 1989. Disponível em: <http://www.oitbrasil.org.br/node/513>. Acesso em: 24 jun. 2017.

ORGANIZAÇÃO INTERNACIONAL DO TRABALHO (OIT). Convenção 169 é o instrumento para inclusão social dos povos indígenas. 2013. Disponível em: <http://www.oitbrasil.org.br/content/ convencao-169-e-o-instrumento-para-inclusao-social-dos-povos-indigenas>. Acesso em: 30 jun. 2017.

ORGANIZAÇÃO INTERNACIONAL DO TRABALHO (OIT). O que é trabalho decente. 2017. Disponível em: <http://www.oitbrasil.org.br/content/o-que-e-trabalho-decente>. Acesso em: 27 jun. 2017.

PECQUEUR, B. Le Développement. Syros, Alternatives Economiques. Économie rurale. $\mathrm{N}^{\circ} 197$, 1990, p. 53-55. Disponível em: <http://www.persee.fr/doc/ecoru_o013-0559_1990_num_197_1_4063_ t1_0053_00oo_4>. Acesso em: 13 out. 2017.

RIGOTTO, Raquel Maria. Inserção da saúde nos estudos de impacto ambiental: o caso de uma termelétrica a carvão mineral no Ceará. Ciência \& Saúde Coletiva. Rio de Janeiro: v. 14. n. 6. p. 2049-2059, dez. 2009.

SACHS, I. Ecodesenvolvimento: Crescer Sem Destruir. São Paulo: Vértice, 1986.

SACHS, I. Stratégies de l'Écodeveloppement. Paris: Les Éditions Ouvrières, 1980.

SEN, Amartya. Desenvolvimento como liberdade. São Paulo: Companhia das Letras, 2010.

SENA, Tânia Conceição. Trabalhadores nos canteiros de obras da UHE belo monte-altamira: condições de saúde e políticas públicas. 293f. Dissertação (Desenvolvimento Sustentável do Trópico Úmido) - UFPA, Belém, 2014. Disponível em: <http://www.ppgdstu.propesp.ufpa.br/ARQUIVOS/ Dissertacoes/2014/T\%C3\%82NIA\%2oSENA\%2oCONCEI\%C3\%87\%C3\%83O.pdf>. Acesso em: o1 jul. 2017. 
SCHEININ, Martin. What are Indigeous peoples? In CHEININGHANEA, Nazila; ZNTHAKI, Alexandra. Minorities, peoples and self-determination. Boston: Martinus Nijhoff Publishers, 2005.

VACCARO, Stefania Becattini. Direito ao Desenvolvimento e Integração Regional. In: PAGLIARINI, Alexandre Coutinho. DIMOULIS, Dimitri (Coord.). Direito constitucional internacional dos direitos humanos. Belo Horizonte: Fórum, 2012.

THOMAS, Jennifer Ann. A ferro e Ouro. Revista Veja, São Paulo: Editora Abril, ano. 5o. n. 2o. ed. 2530. p. 84-91, mai. 2017.

TRIGUEIRO, André (et al). Educando para um Novo Olhar, Comunicando para um Novo Saber. In: TRIGUEIRO, André. Mundo sustentável 2: novos rumos para um planeta em crise. São Paulo: Globo, 2012.

YAMADA, Erica M; OLIVEIRA, Lúcia Alberta Andrade de. A convenção 169 da OIT e o direito à consulta livre, prévia e informada. Brasília: Funai/GIZ, 2013. Disponível em: <http://www.consultaprevia.org/ files/biblioteca/fi_name_archivo.325.pdf.>. Acesso em: 28 jun. 2017. 